International Journal on Information Sciences and Computing, Vol.3, No.1, January 2009

\title{
APPLYING SIX-SIGMA IN HEALTH SERVICE: A STUDY OF CRITICAL SUCCESS FACTORS, CRITICAL TO QUALITY CHARACTERISTICS AND KEY PERFORMANCE INDICATORS IN MEDIUM SCALE HOSPITALS
}

\author{
G. Dileep ${ }^{1}$, S.S. Rau², \\ ${ }^{1}$ Research scholar, ${ }^{2}$ Registrar, \\ ${ }_{1,2}$ Sathyabama University, Rajiv Gandhi Road, Chennai, India \\ E-mail : 'dileep301963@yahoo.com
}

\section{Abstract}

The benefits of six-sigma quality standard implementation are realized by the manufacturing sector very well and most of the cases reaped astounding benefits. This paper presents an extensive review on the services, six-sigma, and study the Critical Success Factors, Critical to Quality Characteristics and Key Performance Indicators in medium scale hospitals in Tamilnadu, India. Can health care approach the near perfection of Six Sigma in actual practice? . General Electric has begun to apply the same Six Sigma methods that worked to improve its manufacturing processes to its other, more service-oriented businesses. We believe, however, that asking this question must not be an excuse for failing to embark on the journey. Health care now frequently produces defects at rates as high as 500,000 per million-as exemplified in failures to recognize and treat clinical depression (Wells et al. 1989) or control hypertension (Udvarhelyi et al. 1991). Enough examples of improvement exist to conclude that we can do much better. In order to improve health service quality focus on health service process is necessary. Six-sigma is a philosophy which also concentrates on the improvement of process. So, six-sigma if properly applied can be useful for health services. The wider applicability of six-sigma depends on identification of key performance indicators (KPIs) for different types of health service processes. A case study is conducted in a medium scale hospital to identify, analyze and rank the critical success factors for Six sigma implementation available in literature, critical to quality characteristics (CTQs),KPIs and hurdles in the hospitals which affect possible quality improvements. This study will be helpful to both practitioners and researchers.

Key words : Health Services, Six-Sigma, Critical success factors, Key Performance Indicators, CTQs

\section{INTRODUCTION}

Quality management has long been established as an important management strategy for achieving competitive advantage. Traditional quality concepts like Statistical Process Control (SPC), Zero Defects and Total Quality Management (TQM), have been key players for many years. While six-sigma is a more recent quality improvement initiative to gain popularity and acceptance in many industries across the globe (Hendry and Nonthaleerak]). six-sigma provides a framework which unites the basic quality tools with high-level management support.

However, most service industries still do not use the basic aspects of SPC. In fact they can benefit significantly by implementing both SPC and six-sigma. The implementation of six-sigma helped the industries like GE (Finance, Health Care), Citibank and a few other service industries to drive defects/errors out of their delivery process and create success stories for others to follow.

The limitation of six-sigma in service industries is that the features of service industries are not uniform. The application of six-sigma and its benefits are limited to some specific types of services like health care and banks. This paper aims to identify the Critical Success Factors, critical to quality characteristics(CTQs), and key performance indicators (KPIs) for medium scale hospitals..

\section{APPLICATION OF SIX SIGMAIN HEALTH SERVICE:}

Service is defined in various ways, by different researchers. Service research is mainly dominated by the marketing. The service definitions, classification schemes, and models are mainly from the marketing perspective. The other major contributor in service research is operations management.

\section{A. Service Definition}

Even though the concept of service goes back to 1950s but still there are no accepted definition of service. The earliest approach to define service is by Shostack, in which the author feels that services are rendered, it is experienced. A service cannot be stored on a shelf, touched, tasted or tried on for a size. Services are generally obtained by engaging an interactive process with the provider, Harvey Vargo and Lusch defines service as the application of specialized competences (skills and knowledge), through deeds, processes and performances for the benefit of another entity or entity itself. Woodall feels that service can or could mean any or all of the following.

- The entire manifestation of a business or not-forprofit structure perceived to reside within the service sector (e.g. restaurant, insurance company, local council repair depot) service as an organization . 
- The key commercial outputs of a service organization (e.g. bank account, insurance policy, and holiday) - service as core product.

- Any peripheral activity designed to enhance the delivery of a core product (e.g. Provision of a courtesy car, complimentary coffee) - service as product augmentation.

- Any product- or customer-oriented activity that takes place after the point of delivery (monitoring, repair, up-dating) - service as product support.

- Service as a mode of behaviour (helping out, giving advice) - service as an act.

- There are several other definitions but the most widely used definition of service is based on its characteristics of intangibility, heterogeneity, inseparability and perishability given by Parasuraman etal .

\section{B. Service Models}

The service research is very rich in context of definitions, models and measurement issue. A model attempts to show the relationships that exist between salient variables. It is a simplified description of the actuality. The primary aim of the review of models is to enable the management to enhance the "quality" of the organization and its offering in a systematic manner. Each of these models is representative of a different point of view, Ghobadian. From 1984 to till date there are around 22 service models. These models are not 22 different models but are interconnected in some way to each other. The review of these models shows that there does not seem to be a well- accepted conceptual definition and model of service quality nor there is any generally accepted operational definition of how to measure service quality. However, majority of models and definitions support the view of evaluating service quality by comparing their service quality expectation with their perceptions of service quality they have experienced, Deshmukh et al .
Table 1

\section{SERVICE QUALITY MODELS}

\begin{tabular}{|c|c|c|}
\hline 1 & Technical and functional quality model & Grönroos (1984) \\
\hline 2 & GAP model & Parasuraman et al (1985 \\
\hline 3 & Attribute service quality model & Haywood - Farmer (1988) \\
\hline 4 & Synthesized model of service quality & Brogowicz et al (1990) \\
\hline 5 & Performance only model & Cronin \& Taylor (1992) \\
\hline 6 & $\begin{array}{l}\text { Ideal value model of service } \\
\text { quality }\end{array}$ & Mattsson (1992) \\
\hline 7 & Evaluated performance and normed quality model & Teas (1993) \\
\hline 8 & IT alignment model & Berkley \& Gupta (1994) \\
\hline 9 & Attribute and overall affect model & Dabholkar (1996) \\
\hline 10 & $\begin{array}{l}\text { Model of perceived service quality } \\
\text { and satisfaction }\end{array}$ & $\begin{array}{l}\text { Spreng \& Mackoy } \\
\text { (1996) }\end{array}$ \\
\hline 11 & PCP attribute model & Philip \& Hazlett (1997) \\
\hline 12 & Retail service quality and perceived value model & Sweeney et al (1997) \\
\hline 13 & $\begin{array}{l}\text { Service quality, customer value and customer } \\
\text { satisfaction model }\end{array}$ & Oh (1999) \\
\hline 14 & Antecedents and mediator model & Dabholkar et al (2000) \\
\hline 15 & Internal service quality model & Frost \& Kumar (2000) \\
\hline 16 & $\begin{array}{l}\text { Internal service quality DEA } \\
\text { model }\end{array}$ & $\begin{array}{l}\text { Soteriou \& Stavrinides } \\
(2000)\end{array}$ \\
\hline 17 & Internet banking model & $\begin{array}{l}\text { Broderick \& Vachirapornpuk } \\
(2002)\end{array}$ \\
\hline 18 & IT-based model & Zhu et al (2002 \\
\hline 19 & Model of e-service quality & Santos (2003) \\
\hline
\end{tabular}

Source: literature review

\section{Six-sigma}

Six-sigma is a philosophy, a measure, and a methodology that provides the business with the perspective and tools to achieve new levels of performance both in services and products, Basem and Roy.

\section{a) Philosophy}

Six-sigma is an operating philosophy that can be shared beneficially by everyone: customers, shareholders, employees and suppliers. Fundamentally, it is also a customer-focused methodology that drives out waste, raises levels of quality, and improves the financial performance of organizations to breakthrough levels.

Six-sigma's target for perfection is to achieve no more than 3.4 defects, errors or mistakes per million opportunities whether it involves the design andproduction of a product or a customer-oriented service process. It is from this target that the "Six-Sigma" name originated.

A process with less variation will be able to fit more standard deviations or sigmas between the process center and the nearest specification limit than a process that 
is highly variable. The greater the number of sigmas within the specifications, the fewer the defects. The smaller the variation, the lower the cost.

The higher the number of sigmas, the more consistent the process of delivering a good product or customer service. Asix-sigma level of performance means that we can fit in six standard deviations or sigmas between the process center and the nearest specification limit.

There are around sixty-six tools and two major approaches to accomplish six-sigma levels of performance. When dealing with an existing process, the process improvement method, also known as DMAIC (Define, Measure, Analyze, Improve and Control), can be used and if there is a need for a new process, the design for six-sigma (DFSS) method can be used.

\section{b) Measure}

The roots of sigma as a measurement standard go back to Fredrick Gauss, who introduced the concept of normal curve or distribution. Walter Shewart introduced threesigma as a measurement of output variation in 1922 and stated that process intervention was needed when the output went beyond this limit. The three-sigma concept is related to process yield of 99.973 percent and represented a defect rate of 2,600 per million which was adequate for most manufacturing units until the early 1980s, Raisinghani etal .

In 1980s, Motorola introduced six-sigma, which revolutionized the scope and use of quality systems in business today. The basic elements of six-sigma like, SPC, Failure Mode Effect Analysis (FMEA), gage repeatability and reproducibility and other tools have been in use for some time. Actually, six-sigma provides a framework which unites these basic quality tools with high-level management support.

Presently around 66 six-sigma tools have been identified. There are also some classification schemes available, like one provided by ASQ (American Society for Quality) and another is Tool Matrix provided by Tague in 1995.

\section{c) Methodology}

DMAIC (Define, Measure, Analyze, Improve and Control)

This is used mostly for existing processes. This approach not only makes use of six-sigma tools, it also incorporates other concepts such as financial analysis and project schedule development.
TABLE 2. DMAIC METHODLOGY

\begin{tabular}{|l|l|}
\hline \multicolumn{1}{|c|}{ Phase } & \multicolumn{1}{|c|}{ Description } \\
\hline Define & $\begin{array}{l}\text { Identify, evaluate and select projects; prepare the mission; } \\
\text { and select and launch the team }\end{array}$ \\
\hline Measure & $\begin{array}{l}\text { Measure the size of the problem, document the process, identify } \\
\text { key customer requirements, determine key product } \\
\text { characteristics and process parameters, document potential failure } \\
\text { modes and effects; theorize on the cause or determinants of } \\
\text { performance }\end{array}$ \\
\hline Analyse & $\begin{array}{l}\text { Plan for data collection; analyze the data and establish and confirm the } \\
\text { "vital few" determinants of performance }\end{array}$ \\
\hline Improve & $\begin{array}{l}\text { Design and carry out experiments to determine the } \\
\text { mathematical cause-effect relationships and optimize the process }\end{array}$ \\
\hline Control & Design controls; make improvements, implement and monitor \\
\hline
\end{tabular}

Source: literature review

DFSS (Design for Six-Sigma)

The DMAIC methodology is excellent when dealing with an existing process in which reaching the entitled level of performance will provide all of the benefits required. When a new process is to be implemented then DFSS provides a disciplined and rigorous approach to service, process and product design in order to meet customer requirements at launch. One of the various approaches for DFSS is tabulated below

TABLE 3. DFSS METHODOLOGY

\begin{tabular}{|l|l|}
\hline \multicolumn{1}{|c|}{ Activities } & \multicolumn{1}{|c|}{ Description } \\
\hline Concept development & $\begin{array}{l}\text { Product functionality is established based on customer requirements, } \\
\text { technology capabilities and economics realities }\end{array}$ \\
\hline Design development & $\begin{array}{l}\text { Products and process performance that is required to fulfill the } \\
\text { product or service requirements }\end{array}$ \\
\hline Design optimization & Seek to minimize the impact of variation \\
\hline Design verification & $\begin{array}{l}\text { Ensures the capability of the production system meets the } \\
\text { customer requirements }\end{array}$ \\
\hline
\end{tabular}

Source: literature review

\section{E. E. Application of Six-Sigma to Services:}

Several researchers (Antony, Hensley and Dobie, Sehwall and Yong ) have tried to identify the factors which are helpful for successful implementation of sixsigma in services. Some of these factors include:

- Organizational experience with improvement programs

- Organizations with an established quality program

- Linking six-sigma to business strategy

- Customer focus

- Top management commitment

- Organizational infrastructure

- Training and education

- Focus on selecting and measuring the correct metrics 
- Identify the benefits and work to maintain the financial results

Despite well developed methodologies and tools, it is felt that six-sigma is still not widely used in services. Its application is limited to some specific service industries like health care and banks. As services are not uniform, it is better to understand the process before applying the sixsigma tools and methodologies In the following part, the paper presents an analysis of the service process done as a case study in medium scale hospitals.

Service processes are all non-manufacturing operations and activities, either in non-manufacturing industries, or within organizations that manufacture. The major segments of service sector are: -

- Banking

- Healthcare

- e-Commerce

- Food Services

- Retail Sales

- Call-center

- Tele-communication

- Aviation

- Hospitality

- Legal

- Education

- Entertainment

\section{III.CASE STUDY}

As mentioned previously, the application of sixsigma is mainly limited to health care and banks. To some extent its application can be found in hospitality and call centers. The main focus of services as well as sixsigma is to improve processes. The process control variables or critical to quality (CTQ) characteristics are an important aspect to improving processes. Along with control variables the outcome or performance indicators due to the application of six-sigma are also a major aspect.

The case study done here focuses on the critical success factors, CTQs and KPIs. The study done here on 12 medium scale hospitals those who have both economic and social objective over the business of health care. The chief medical officers are interviewed and the information given analyzed to give the following results.

\section{A. CRITICAL SUCCESS FACTORS}

The critical success factors are ranked by the different chief medical officers of the twelve hospitals and the mean value of each factor is as below.

\section{TABLE 4.}

\begin{tabular}{|c|c|c|}
\hline CRITICAL SUCCESS FACTORS & MEAN & $\begin{array}{l}\text { PERCENTAGE OF } \\
\text { HOSPITALS } \\
\text { GIVING TOP } 5 \\
\text { RANK }\end{array}$ \\
\hline $\begin{array}{l}\text { 1. Top management leadership \& commitment are essential to Six } \\
\text { Sigma QMS success. Top management should act as key driver in } \\
\text { continuous improvements, communicate to employees about } \\
\text { organizational goals, and establish an environment for supporting } \\
\text { organizational \& employee learning. }\end{array}$ & 2 & 100 \\
\hline $\begin{array}{l}\text { 2. A well-implemented customer management system is critical to } \\
\text { Six Sigma QMS success. Processes need to be established in order to } \\
\text { monitor customer satisfaction levels, to receive customer feedback, } \\
\text { and to resolve customer concerns }\end{array}$ & 2.17 & 100 \\
\hline $\begin{array}{l}\text { 3. The education and training system should provide continuous } \\
\text { courses to employees for equipping them with quality-related } \\
\text { knowledge and problem-solving skills. }\end{array}$ & 3.25 & 91.6 \\
\hline $\begin{array}{l}\text { 4. A well-organized information and analysis system should be } \\
\text { designed to collect the performance measures in order to monitor the } \\
\text { quality of key business processes. }\end{array}$ & 4.67 & 75 \\
\hline $\begin{array}{l}\text { 5.A well-implemented process management system that identifies, } \\
\text { improves, and monitors the key business processes has a positive } \\
\text { impact on Six Sigma QMS success. The quality assurance system, } \\
\text { work unit performance measures, and statistical techniques are } \\
\text { essential to process management. }\end{array}$ & 5.67 & 50 \\
\hline $\begin{array}{l}\text { 6. A well-developed strategic planning system must translate into } \\
\text { executable action plans with related performance measurements. The } \\
\text { necessary human \& financial resources must be allocated to support } \\
\text { the implementation of business action plans. }\end{array}$ & 9.41 & 0 \\
\hline $\begin{array}{l}\text { 7. A well-developed supplier management system, where the main } \\
\text { criteria for selecting suppliers is based on quality aspects, has a } \\
\text { positive impact on Six Sigma QMS success. Processes need to be } \\
\text { built in order to monitor the quality performance levels of suppliers. }\end{array}$ & 7.58 & 0 \\
\hline $\begin{array}{l}\text { 8. Throughout the organization, from management to employees, } \\
\text { equipping all with quality tools has a positive impact on Six Sigma } \\
\text { QMS success. Quality tools should be used in production and non- } \\
\text { production processes. }\end{array}$ & 5.67 & 8.33 \\
\hline $\begin{array}{l}\text { 9.A well-developed human resource management system has a } \\
\text { positive impact on Six Sigma QMS success. A job advancement } \\
\text { system is important to human resource development. Various methods } \\
\text { are developed to facilitate the communication between the } \\
\text { organization and its employees. To promptly improve performance, } \\
\text { employees need to receive their performance feedback from their } \\
\text { supervisors. }\end{array}$ & 3.67 & 83.33 \\
\hline $\begin{array}{l}\text { 10. A well-developed competitive benchmarking system should be } \\
\text { capable of collecting market and competitors' information. The process } \\
\text { of benchmarking information collection needs to be evaluated to } \\
\text { ensure its effectiveness }\end{array}$ & 9.42 & 0 \\
\hline
\end{tabular}

Source: Primary Data

TABLE 5.

THE WILCOXON-WILCOX TEST FOR COMPARISON OF MULTIPLE FACTORS

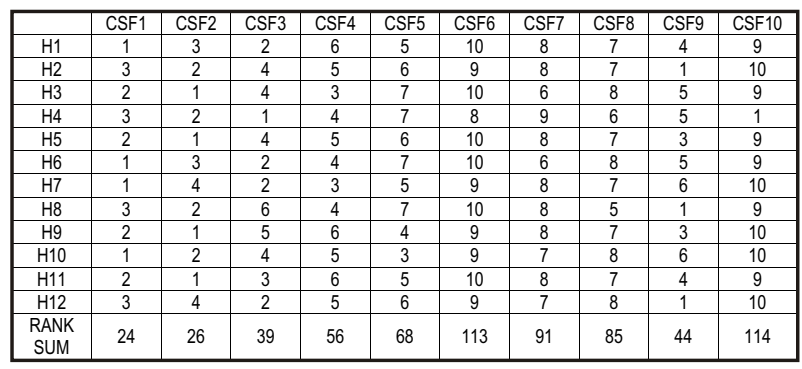

Source: Primary Data 
TABLE 6. RANK SUM DIFFERENCES

\begin{tabular}{|c|c|c|c|c|c|c|c|c|c|c|}
\hline & CSF1 & CSF2 & CSF3 & CSF4 & CSF5 & CSF6 & CSF7 & CSF8 & CSF9 & CSF10 \\
\hline CSF1 & - & 2 & 15 & 32 & 44 & $89^{*}$ & $67^{*}$ & $61^{*}$ & 20 & $90^{*}$ \\
\hline CSF2 & - & - & 13 & 30 & 42 & $87^{*}$ & $65^{*}$ & $59^{*}$ & 18 & $88^{*}$ \\
\hline CSF3 & - & - & - & 17 & 29 & $74^{*}$ & 52 & 46 & 5 & $75^{*}$ \\
\hline CSF4 & - & - & - & - & 12 & 45 & 35 & 29 & 12 & $58^{*}$ \\
\hline CSF5 & - & - & - & - & - & 45 & 23 & 17 & 24 & 46 \\
\hline CSF6 & - & - & - & - & - & - & 22 & 28 & $69^{*}$ & 0 \\
\hline CSF7 & - & - & - & - & - & - & - & 6 & 47 & 23 \\
\hline CSF8 & - & - & - & - & - & - & - & - & 41 & 29 \\
\hline CSF9 & - & - & - & - & - & - & - & - & - & $70^{*}$ \\
\hline CSF10 & - & - & - & - & - & - & - & - & - & - \\
\hline
\end{tabular}

For $K=10, n=12$ and $a=0.01$ the critical value $=$ 54.1 (from tables)

Hence the comparisons of CSFs having absolute value above 54.1 are significant. ( ${ }^{*}$ marked).

From the table CSF1 - Top management leadership \& commitment significantly differs from CSF6- A w e II developed strategic planning system, CSF7- A welldeveloped supplier management system, CSF8equipping all with quality tools and CSF10- A welldeveloped competitive benchmarking system.

CSF2 significantly differs from CSF6- A well-developed strategic planning system, CSF7- A well-developed supplier management system, CSF8- equipping all with quality tools and CSF10-A well-developed competitive benchmarking system.

CSF3- The education and training system significantly differs from CSF6- A well-developed strategic planning system, and CSF10- A well-developed competitive benchmarking system.

CSF4- A well-organized information and analysis system significantly differs from CSF10- A well-developed competitive benchmarking system.

CSF6- A well-developed strategic planning system significantly differs from CSF9-A well-developed human resource management system.

CSF9- A well-developed human resource management system, significantly differs from CSF10-A well-developed competitive benchmarking system.

Hence the hypothesis of all critical success factors have the same effect is rejected. The critical success factors differ on their effect.

\section{THE RANK CORRELATION TEST FOR AGREEMENT IN MULTIPLE JUDGEMENTS}

This test is applied to verify the agreement between ranking the critical success factors.
TABLE 7.

\begin{tabular}{|c|c|c|c|c|c|c|c|c|c|c|}
\hline & CSF1 & CSF2 & CSF3 & CSF4 & CSF5 & CSF6 & CSF7 & CSF8 & CSF9 & CSF10 \\
\hline RANK SUM & 24 & 26 & 39 & 56 & 68 & 113 & 91 & 85 & 44 & 114 \\
\hline MEAN & 66 & 66 & 66 & 66 & 66 & 66 & 66 & 66 & 66 & 66 \\
\hline DIFFERENCE & -42 & -40 & -27 & -10 & 2 & 47 & 25 & 19 & -22 & 48 \\
\hline $\begin{array}{c}\text { SQUARE OF } \\
\text { THE } \\
\text { DIFFERENCE }\end{array}$ & 1744 & 1600 & 729 & 100 & 4 & 2209 & 625 & 361 & 484 & 2304 \\
\hline
\end{tabular}

The test statistic $\mathrm{F}=\mathrm{S}_{1}{ }^{2} / \mathrm{S}_{2}{ }^{2}$

Where $S_{1}^{2}=D_{1} / K-1$

$$
\begin{aligned}
& S_{2}^{2}=D_{2} / K(n-1) \\
& D_{1}=S_{D} / n \\
& D_{2}=S-D_{1} \\
& S=n K\left(K^{2}-1\right) / 12 \text { and }
\end{aligned}
$$

$S_{D}=$ sum of squares of the differences between subjects mean ranks and the overall mean rank.

$$
\text { Here } \begin{aligned}
S_{D} & =10180 \\
& D_{1}=848.33 \\
& D_{2}=141.58
\end{aligned}
$$

$\mathrm{F}=73.07$

\section{From tables $F$ value is 1.96}

The hypothesis of agreement between the ranks is rejected. There is no agreement between the ranks given by the different medical officers. This explains the variability in the service environment of the same sector.

\section{B. critical to Quality Characteristics:}

The CTQs identified for the health care process which are weighed by the 12 chief medical officers are given in the table.Table8

\section{TABLE 8. WEIGHTAGE OF DIFFERENT CTQS OF MEDIUM SCALE HOSPITALS}

\begin{tabular}{|l|c|c|c|c|c|c|}
\hline \multirow{2}{*}{ CTQS } & \multicolumn{5}{c|}{ weightage } & Mean \\
\cline { 2 - 7 } & $\mathbf{1}$ & $\mathbf{2}$ & $\mathbf{3}$ & $\mathbf{4}$ & $\mathbf{5}$ & weight \\
\hline Patient satisfaction & 0 & 0 & 3 & 4 & 5 & 4.17 \\
\hline Speed and accuracy of admission & 0 & 0 & 1 & 2 & 9 & 4.67 \\
\hline Care coordination by nursing staff & 0 & 0 & 3 & 6 & 3 & 4 \\
\hline Accuracy of lab results & 0 & 0 & 0 & 0 & 12 & $\mathbf{5}$ \\
\hline Rapid emergency room treatment & 0 & 2 & 4 & 5 & 1 & 3.42 \\
\hline Inventory control & 2 & 5 & 3 & 1 & 1 & 3.25 \\
\hline Billing accuracy & 1 & 3 & 3 & 3 & 2 & 3.17 \\
\hline Supply chain & 2 & 3 & 4 & 2 & 1 & 2.75 \\
\hline Cost of processes & 2 & 2 & 3 & 2 & 3 & 3.17 \\
\hline Staffing level & 1 & 3 & 4 & 2 & 2 & 3.08 \\
\hline Waiting Time & 2 & 3 & 2 & 3 & 2 & 3.33 \\
\hline Bed availability & 1 & 5 & 3 & 2 & 1 & $\mathbf{2 . 5 8}$ \\
\hline Room comfort & 3 & 4 & 2 & 2 & 1 & $\mathbf{2 . 5}$ \\
\hline Surgery scheduling & 1 & 3 & 2 & 2 & 4 & 3.42 \\
\hline Externally hired specialty & 0 & 0 & 3 & 6 & 3 & $\mathbf{4}$ \\
\hline End of life care & 2 & 3 & 2 & 3 & 2 & 3 \\
\hline
\end{tabular}

Source: Primary Data 
Considering the mean weight above 4 are more critical the significant CTQs are

Accuracy of lab results, Speed and accuracy of admission, Patient satisfaction, Care coordination by nursing staff, externally hired specialty. The balance CTQs are less critical in the order of their mean weight.

\section{C.key Performance Indicators}

The KPIs identified for the health care process which are weighed by the 12 chief medical officers are given in the table.

TABLE 9.

WEIGHTAGE OF DIFFERENT KPIS OF MEDIUM SCALE HOSPITALS

\begin{tabular}{|l|c|c|c|c|c|c|}
\hline \multicolumn{1}{|c|}{ Key Performance Indicators } & \multicolumn{7}{|c|}{ weightage } & Mean \\
\cline { 2 - 6 } & $\mathbf{1}$ & $\mathbf{2}$ & $\mathbf{3}$ & $\mathbf{4}$ & $\mathbf{5}$ & $\mathbf{3}$.ight \\
\hline Throughput & 2 & 2 & 2 & 3 & 3 & 3.25 \\
\hline Cost/Procedure & 1 & 0 & 4 & 1 & 6 & 3.92 \\
\hline Care & 0 & 0 & 3 & 4 & 5 & 4.17 \\
\hline Wait Time & 1 & 3 & 4 & 2 & 2 & 3.08 \\
\hline Service Time & 1 & 2 & 3 & 2 & 4 & 3.50 \\
\hline Information Conveyance Time & 0 & 2 & 1 & 5 & 4 & 3.91 \\
\hline Cost per Unit of Service & 1 & 1 & 3 & 4 & 3 & 3.58 \\
\hline Labour Productivity & 2 & 1 & 5 & 2 & 2 & 3.08 \\
\hline Clinical excellence & 0 & 0 & 4 & 2 & 6 & 4.17 \\
\hline Patient safety & 0 & 0 & 0 & 4 & 8 & 4.67 \\
\hline Efficiency & 2 & 2 & 3 & 3 & 2 & 3.08 \\
\hline Time-to-serve & 1 & 1 & 3 & 2 & 5 & 3.75 \\
\hline Quality of the service & 0 & 0 & 2 & 4 & 6 & 4.33 \\
\hline Customer satisfaction & 0 & 2 & 2 & 4 & 4 & 3.83 \\
\hline Reduced variation & 4 & 2 & 2 & 3 & 1 & 2.58 \\
\hline Staff development & 0 & 3 & 1 & 2 & 4 & 3.25 \\
\hline Timely and quality service & 0 & 3 & 4 & 5 & 4.17 \\
\hline Positive customer experience & 0 & 1 & 3 & 5 & 3 & 3.83 \\
\hline Revenue enhancement & & 2 & 5 & 5 & 4.25 \\
\hline Employee satisfaction & 0 & 3 & 4 & 5 & 4.17 \\
\hline
\end{tabular}

Source: Primary DataConsidering the mean weight of more than 4 indicates the performance better the important KPIs are Patient safety, Quality of the service, Positive customer experience

Care, Clinical excellence, Timely and quality service, Revenue enhancement.

The hurdles identified by the hospitals are

1. Adequately Skilled Human Resources

2. Documentation

3. Non cost effective Infrastructure

4. Insurance denials

\section{CONCLUSION}

This paper reviews about services, six-sigma and the application of six-sigma in health services. The review identified that the application of six-sigma is still not wide spread in services as in manufacturing. Wherever applied, it is also limited to some particular departments like in health care. It is mostly applied to some particular laboratories and not in the overall hospital. The extent of application is more in developed countries than developing countries.

The case study done here provides an understanding of the alignment of critical Success Factors existing with medium scale hospitals the rating of CTQs and KPIs in the medium scale health service environment. . This finding can be helpful in the wider application of sixsigma in the hospitals.

The restriction on the length of the paper and the ongoing case study are the two aspects which limits further discussion. Future work will involve identification of the phases in the development of the implementation methodology with respect to the Dominant critical success factors, identified highly Critical to Quality characteristics and better Key Performance Indicators in the context of continuous improvement.

\section{REFERENCES}

[1] A.Parasuraman, V.A. Zeithaml and L.L. Berry, "A Conceptual Model of Service Quality and Its Implication for Future Research," Journal of Marketing, Vol. 49 No. 4, pp. 41-50, 1985

[2] A.R. Benedetto, "Adapting Manufacturing - Based Six Sigma Methodology to the Service Environment of a Radiology Film Library," Journal of Healthcare Management, Vol. 48 No.4, pp.263-280, 2003.

[3] C. Grönroos, "A Service Quality Model and its Marketing Implications," European Journal of Marketing, Vol. 18 No. 4, pp. 36-44, 1984.

[4] C. Voss, R. Silvestro, L. Fitzgerald and R. Johnston, "Towards a Classification of Service Processes," International Journal of Service Industry Management, Vol.3, No.3, pp. 62-75, 1992.

[5] C.H. Lovelock, "Classifying Services to Gain Strategic Marketing Insights," Journal of Marketing, Vol.47 No.3, pp. 9-20, 1983.

[6] D.H. Stamatis, Six Sigma Fundamentals, Productivity Press, New York, 2004.

[7] G.L. Shostack, "Breaking Free from Product Marketing," Journal of Marketing, April, pp. 73-80, 1977. 
[8] J. Antony, "Six-Sigma in the UK Service Organizations: Results from a Pilot Survey," Managerial Auditing Journal, vol.19, no.8, pp. 10061013, 2004.

[9] J. Harvey, "Service Quality: A Tutorial," Journal of Operations Management, Vol. 16, pp. 583-597, 1998.

[10] J. R. Evans and W. M. Lindsay, The Management and Control of Quality, Mason, Ohio: South Western, 2005.

[11] J.S. Oakland and J.A. Dotchin, "Total Quality Management in Services Part 1: Understanding and Classifying Services," International Journal of Quality and Reliability Management, Vol.11, No. 3, pp. 9-26, 1994.

[12] L. Sehwall and C. De Yong, "Six Sigma in Health Care," International Journal of Health Care Quality Assurance, Vol. 16 No. 6, pp. 1-5, 2003.

[13] M. Schimdt and S. Aschkenase, "The Building Blocks ofService," Supply Chain Management Review, July-Aug, pp.34-40, 2004. P., pp. 491-505, 2005.

[14] A.S. Johnstone, et al. "Ancillary Services in the Health Carelndustry: Is Six-Sigma Reasonable?" Quality management inHealth Care, Vol. 12 No. 1, pp. 53-63, 2003.

[15] S.G. Deshmukh, N. Seth and P. Vrat, "Service Quality Models:AReview," International Journal of Quality \& Reliability Management, Vol.22, No.9, pp. 913-949, 2005.
[16] T. Woodall, "Six Sigma and Service Quality: Christian Grönroos Revisited," Journal of Marketing Management, Vol. 17, pp. 595-607, 2001.

[17] A. Ghobadian, S. Speller, and M. Jones, "Service Quality: Concepts and Models," International Journal of Quality \& Reliability Management, Vol. 11 No. 9, pp. 43-66, 1994.

[18] R. Rucker, "Citibank Increases Customer Loyalty with Defect - Free Processes," Association for Quality and Participation, pp. 32-36, 2000

[19] R.C.H. Chua, "What you need to know about Six-Sigma?" Productivity Digest, Dec, pp. 37-44, 2001.

[20] R.C.H. Chua and J.Y. Yun, "Samsung Uses Six sigma to Change its Image," ASQ Six - Sigma Forum Magazine, Vol.2 No.1, pp.13-16, 2002.

[21] Gopal K.Kanji, 2006, 100 statistical tests,New Delhi, Sage Publications, Page no 130,133

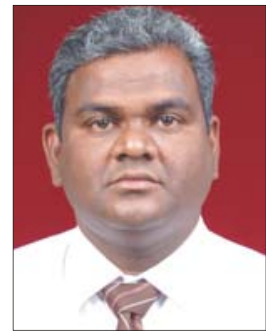

G.Dileep

Research Scholar Sathyabama University. He has 15 years of Industry experience and 7 years of Academic experience. He has organized several workshops and has presented several papers in national and international conferences. His research interest is Total Quality Management and Quality Control. 